\title{
Lesão contratual e necessidade: considerações acerca da análise econômica dos contratos lesivos
}

Leandro Martins Zanitelli ${ }^{1}$

\section{Resumo}

$\mathrm{O}$ artigo trata da análise econômica da lesão por premente necessidade. $\mathrm{Na}$ primeira parte, estuda-se a relação entre lesão e repartição do excedente contratual, bem como a ideia, defendida por Trebilcock e, em certa medida, Craswell, de que a intervenção judicial fique restrita aos casos de contratos realizados sob monopólio situacional. Defende-se que tal solução peca por não dar devido tratamento aos casos de monopólio não situacional (ou “estrutural”) com os quais não costumam se ocupar os órgãos antitruste, bem como porque falta, para o monopólio situacional, uma das razões de eficiência pelas quais se costuma justificar a repressão aos monopólios em geral. Na segunda parte, examina-se a defesa da intervenção em contratos firmados em situação de necessidade - feita, entre outros, por Shavell- como meio de minimizar custos que, em grande parte, são suportados pelas partes antes mesmo de verificadas as circunstâncias sob as quais o contrato é celebrado. Discorre-se, aí, fundamentalmente, sobre os conceitos de situação de necessidade engendrada (SNE), situação de necessidade não engendrada (SNN) e custo social, chamando-se a atenção para o papel, muitas vezes pouco explicitado, de certas suposições para uma análise na qual esses conceitos sejam empregados.

Palavras-chave: Lesão. Necessidade. Análise Econômica do Direito. Monopólio Situacional. Situações de Necessidade Engendradas. Custo Social

\footnotetext{
1 Doutor em Direito pela Universidade Federal do Rio Grande do Sul (UFRGS), com estágio de pós-doutorado na Universidade de Hamburgo, Alemanha. Professor dos Cursos de Graduação e Pós-Graduação (Mestrado Acadêmico) em Direito do Centro Universitário Ritter dos Reis (UniRitter). O autor agradece à Fundação de Amparo à Pesquisa do Estado do Rio Grande do Sul (FAPERGS) e ao UniRitter pelo apoio financeiro, bem como a dois pareceristas anônimos pelos comentários a versões anteriores deste artigo.
} 


\section{Introdução}

Segundo o art. 157 do Código Civil, caracteriza-se a lesão "quando uma pessoa, sob premente necessidade, ou por inexperiência, se obriga a prestação manifestamente desproporcional ao valor da prestação oposta." Com base em tal disposição, a doutrina costuma sujeitar a lesão a dois requisitos: o chamado requisito subjetivo, que é atendido pela premente necessidade do contratante vítima ou, alternativamente, pela sua inexperiência, e o requisito objetivo, correspondente à "manifesta desproporção" entre as prestações. ${ }^{2}$ No presente trabalho, desconsidera-se a segunda das duas maneiras pelas quais o requisito subjetivo pode ser satisfeito - isto é, a que diz respeito à inexperiência - concentrando-se a atenção nos casos de lesão por premente necessidade. ${ }^{3}$

O Código Civil deixa a cargo do intérprete determinar o que é a "premente necessidade" a que se refere o art. 157, bem como a "manifesta desproporção" entre as prestações contratuais, limitando-se a observar, quanto a essa última, que deve ser apreciada "segundo os valores vigentes ao tempo em que foi celebrado o negócio jurídico” (art. 157, \$1º. Tal observação serve para atrelar a lesão à ideia de desequilíbrio contratual originário e para apartá-la, em consequência, dos casos de desequilíbrio provocado por fato superveniente - ou, simplesmente, desequilíbrio superveniente - de que trata o art. 478. A relação entre lesão e desequilíbrio originário pouco esclarece, no entanto, sobre o que constitua esse desequilíbrio.

Tema do presente estudo é também o que se costuma designar como "análise econômica do direito" e a tentativa, a partir dos pressupostos dessa análise, de definição dos critérios da lesão por premente necessidade. Trata-se, em outras palavras, da interpretação, sob uma certa ótica (dita "econômica"), dos requisitos da "premente necessidade" e "manifesta desproporção" estipulados pelo art. 157 do Código Civil.

2 COELHO, F. U. Curso de direito civil. São Paulo: Saraiva, 2003. v. 1. p. 331; SILVA, L. R. F. Revisão dos contratos: do código civil ao código do consumidor. Rio de Janeiro: Forense, 1999. p. 79-84.

3 A premente necessidade também é requerida para a caracterização do estado de perigo (Código Civil, art. 156), outra causa de anulação de contratos e negócios jurídicos em geral (Código Civil, art. 171, II). 
Embora a pretensão seja a de submeter a análise econômica da lesão contratual à crítica, é conveniente que se esclareçam, ainda nesta introdução, as razões da atenção dispensada a essa análise, e isso não só devido à resistência enfrentada pelo approach econômico entre nós, como também para instruir com mais exatidão o leitor sobre os objetivos do presente estudo.

Tal como se concebe aqui, a análise econômica do direito é caracterizada pela "tomada de empréstimo" à Economia de uma certa gama de conceitos, os quais se empregam, então, para os fins da ciência jurídica - em especial, para a descrição de situações de fato hipotéticas e suas respectivas consequências jurídicas. Isso faz com que conceitos forjados em uma tradição de pesquisa - como o conceito econômico de "monopólio situacional" - emaranhem-se aos de uma outra tradição - no caso, por exemplo, em que o conceito econômico de "monopólio situacional" sirva para dar conteúdo ao conceito jurídico de "lesão contratual".

É difícil estabelecer de uma vez por todas o quão desejável, ou indesejável, é esse entrecruzar de saberes, e isso não só porque o mérito de trabalhos interdisciplinares como os da análise econômica do direito constitua ele próprio objeto de uma investigação científica sujeita a limites, seja epistemológicos, seja metodológicos. Uma opinião sobre o valor de uma transposição conceitual como a que caracteriza a análise econômica do direito depende de uma avaliação tanto da tradição de pesquisa que serve aí como "doadora" (isto é, do mérito da ciência econômica qua ciência econômica) como da conveniência da transposição em si mesma, a qual pode suscitar diferentes pontos de vista de acordo com o "setor de recepção" (no caso, o setor da ordem jurídica) no qual essa transposição ocorre. Dadas essas dificuldades, o mais prudente talvez seja, em lugar da rejeição pura e simples ou do uso irrefletido, examinar a análise econômica nos pormenores de sua aplicação ao direito, isto é, tendo em vista os resultados dessa análise em cada área de regulação, os quais devem, então, submeter-se a crítica cuidadosa.

Se, ao final, uma investigação assim parecer insatisfatória, pois que inconclusiva - isto é, se não se puder concluir, ao fim e ao cabo, sobre a validade das conclusões da análise econômica para a lesão contratual - isso pode se dever, se bem que à insuficiência do estudo feito, também à incompreensão que corresponde a 
tratar como tarefa da pesquisa em direito unicamente a de recomendar a legisladores e juízes como devem se comportar, ao invés de também tornar explícitos os pressupostos das decisões legislativas e jurisprudenciais juntamente com o conteúdo normativo ou, se se quiser, ideológico, desses mesmos pressupostos.

O artigo é organizado da seguinte maneira. Na primeira parte, examina-se a hipótese de a lesão ser caracterizada como apropriação indevida do excedente (surplus) contratual por uma das partes. As normas de anulação ou revisão contratual por lesão são encaradas aí como normas de combate à referida apropriação ou ao que se designa como exploração de uma das partes pela outra. Para o exame dessa hipótese, interessam, além do conceito de excedente contratual, as distinções entre preços concorrenciais e não concorrenciais e monopólio situacional e não situacional (ou “estrutural”).

Na segunda parte, consideram-se as normas sobre lesão como normas de redução de custos, sobretudo custos de busca (para potenciais beneficiados) e de prevenção (para potenciais vítimas). O conceito central aí é o de "custo social", do qual os conceitos de custos de busca e de prevenção constituem desdobramentos.

\section{Lesão e excedente contratual}

Excedente contratual é a diferença entre os preços de reserva de cada um dos contratantes. Supondo-se que $A$, dono de uma casa, esteja disposto a vendê-la por ao menos $\mathrm{R} \$ 50.000,00$ e que $B$, um potencial comprador, aceite pagar até $\mathrm{R} \$$ $60.000,00$ pela casa de $A$, então o excedente de um contrato entre $A$ e $B$ seria de R $\$$ $10.000,00$, isto é, a diferença entre o preço de reserva de $A$ (o preço mínimo pelo qual ele aceitaria vender, $\mathrm{R} \$ 50.000,00$ ) e o preço de reserva de $B$ (o preço máximo pelo qual ele aceitaria comprar, $\mathrm{R} \$ 60.000,00)$. Embora o excedente contratual seja de $\mathrm{R} \$ 10.000,00$ em qualquer contrato que $A$ e $B$ venham a realizar, a maneira como esse excedente é repartido pode variar de acordo com o preço estipulado. Assim, por exemplo, o excedente seria inteiramente apropriado por $A$ na hipótese de a casa ser vendida por $\mathrm{R} \$ 60.000,00$, inteiramente apropriado por $B$ no caso de uma venda por $\mathrm{R} \$ 50.000,00$ e igualmente repartido entre os contratantes mediante um preço de $\mathrm{R} \$ 55.000,00$. 
Considere-se agora uma hipótese na qual $A$ seja levado a vender algo pelo equivalente ao seu preço de reserva, isto é, uma hipótese em que a parte do excedente contratual da qual $A$ se apropria seja igual ou muito próxima a zero. Para tanto, suponha-se que haja um único potencial comprador, $B$, mas um outro potencial vendedor, $C$. Suponha-se, também, que $C$ tenha uma casa igual a de $A$ para oferecer a $B$ e, finalmente, que o custo no qual $A$ e $C$ incorreram para construção seja o mesmo e equivalente a $\mathrm{R} \$ 50.000,00$. Em tal hipótese, pode-se imaginar que a concorrência de $C$ faça $A$ vender a casa para $B$ por $\mathrm{R} \$ 50.000,00$ ou algo muito próximo disso, já que uma oferta de venda da casa de $A$ por qualquer preço superior a esse seria, provavelmente, superada por uma outra oferta, mais vantajosa, de $C$. Diz-se, em tal caso, que o preço pelo qual $A$ se desfaz da casa é o preço concorrencial.

Alguns esclarecimentos sobre a ideia de preço concorrencial impõem-se aqui. Observe-se que, na hipótese recém imaginada, o preço pelo qual $A$ acaba vendendo o imóvel é não só igual ou muito próximo ao seu preço de reserva, como também que esse preço de reserva corresponde ao valor, para $A$, dos fatores de produção (incluindo o trabalho do próprio $A$ ) empregados para a construção da casa. Isso significa supor não só que $A$ se comporte de maneira a maximizar seus ganhos, e que portanto não esteja, em geral, disposto a se desfazer de um bem por um preço inferior ao custo de produzi-lo, como também a falta de uma contingência que, elevando subitamente a utilidade do dinheiro para $A$, reduza seu preço de reserva a um patamar inferior ao do custo de produção.

Se o preço concorrencial é o que corresponde ao valor, para o agente, dos fatores de produção, preço não concorrencial, ou monopolista, é o que supera o valor desses fatores. Se $A$ e $B$ só podem contratar um com o outro (monopólio bilateral), o preço da venda, considerando-se os preços de reserva antes mencionados, pode ser qualquer um entre R\$50.000,00 e R \$ 60.000,00 e, em consequência, superar o preço concorrencial (o qual, no exemplo, é de R\$50.000,00). Já com a aparição de um segundo potencial comprador, $D$, com preço de reserva igual ao de $B(\mathrm{R} \$ 60.000,00)$, a tendência seria a disputa entre $B$ e $D$ fazer o preço contratual se aproximar do limite dado pelo preço de reserva de ambos, isto é, que o preço (contratual) fique em torno de $\mathrm{R} \$ 60.000,00$. 
Por que a diferença entre preços concorrenciais e não concorrenciais é importante? Trabalhos sobre o custo social de monopólios costumam relacionar esse custo não aos consumidores submetidos a um preço superior ao concorrencial, mas aos que se veem, pela a imposição desse preço, impedidos de consumir. ${ }^{4}$ Isso significa, em outras palavras, que a perda sofrida por $B$ ao pagar um preço superior a $\mathrm{R} \$ 50.000,00$ pela casa de $A$ é uma perda individual que, ao ser compensada pelo ganho equivalente de $A$, inflige custo social nulo. ${ }^{5}$ Imagine-se, no entanto, que $A$ disponha de mais casas para venda, mas que, aproveitando-se de sua posição monopolista, mantenha os preços em patamares superiores ao competitivo. Isso faria com que os imóveis deixassem de ser vendidos para consumidores cujo preço de reserva, apesar de igual ou superior a $\mathrm{R} \$ 50.000,00$, estivesse aquém do exigido por $A$, acarretando, aí sim, uma perda para esses consumidores que, ao não corresponder a a um ganho equivalente para o construtor, constitui uma perda ou custo social. ${ }^{6}$

O fato de a sujeição de $B$ a um preço não competitivo não ser, em si mesma, merecedora de consideração (o que se insinua quando se afirmar não haver aí um "custo social"), mas apenas pelas consequências que esse preço tem para a venda de casas em geral e, mais exatamente, para o volume dessas vendas, é algo que certamente não espanta o leitor em mínima medida familiarizado com o pensar econômico. Não é propósito do presente trabalho pôr em xeque aqui esse modo

4 TULLOCK, G. The welfare costs of tariffs, monopolies, and theft. Western Economic Journal, Fountain Valley, v. 5, n. 3, p. 224-232, 1967; POSNER, R. A. The social costs of monopoly and regulation. The Journal of Political Economy, Illinois, v. 83, n. 4, p. 807-828, 1975.

5 Que a apropriação da totalidade do excedente contratual por $A$ não seja, em si mesma, relevante para uma análise de custos sociais não significa que não haja razões relacionadas a esses custos (razões de eficiência, portanto) para que a lei exija uma repartição mais equânime desse excedente. Além dos incentivos para a redução de custos que a intervenção legal pode criar, examinados na segunda parte deste artigo, argumenta-se que normas legais de limitação de preço podem facilitar a realização de contratos e, por conseguinte, elevar o volume total dos ganhos advindos da cooperação, já que, à falta de um limite a servir como referência ou "ponto focal", a insistência das partes em obter para si a maior parcela possível do excedente contratual pode levar ao fracasso das tratativas para a realização do contrato. Cf., a respeito, BUCKLEY, F. H. Three theories of substantial fairness. Hofstra Law Review, New York, v. 19, p. 33-66, 1990.

6 Supõe-se aí que $A$ não esteja informado sobre os preços de reserva dos consumidores, o que lhe permitiria tirar maior vantagem da posição de monopolista ao exigir de cada consumidor um preço diferente (e igual ao preço de reserva do consumidor em questão). 
de conceber perdas sociais que tem em vista tão-somente a alocação eficiente de recursos, e já não a repartição desses recursos segundo critérios de justiça. A atenção à eficiência dispensada por estudos econômicos já foi assaz debatida em outros lugares, além de estar relacionada, sempre que se atribua à eficiência não apenas o status de objeto mas também o de objetivo (isto é, que se lhe reconheça validade normativa), à defensabilidade do utilitarismo. Quando se trata de contratos, é aliás bem comum postular-se que a eficiência, ainda que não se possa aceitar como fim social último, seja ao menos vista como fim intermédio, cujos resultados indesejáveis sob o ponto de vista da justiça ficariam para ser corrigidos pela atividade estatal em frentes outras que não a contratual, tal como, por exemplo, a da tributação.?

Considerando-se por ora apenas o inconveniente de preços não concorrenciais, isto é, o fato de que, em virtude desses preços, algumas pessoas são deixadas "de fora do mercado" (out of market) ou impedidas de realizar contratos mutuamente vantajosos, questão que se põe é a do tratamento a que esses preços devam estar legalmente submetidos. Deixando-se de lado a hipótese de que os custos da regulação (os custos de repressão aos monopólios) superem os benefícios que dessa regulação advenha (o que levaria a recomendar a simples não intervenção), o que se pergunta, mais exatamente, é se o controle de preços apto a prevenir o custo social dos monopólios deve se realizar judicialmente mediante a aplicação de normas como a da lesão, o que faz com que tal controle se sujeite à provocação do contratante vítima, tenha seu alcance quase sempre limitado a um contrato de cada vez e seja exercido por juízes. Como alternativa, a repressão aos monopólios pode delegar-se a outros órgãos do Estado, os quais, além de constituídos por técnicos com formação variada, estariam autorizados a atuar independentemente de provocação e a adotar medidas outras que não a anulação ou revisão de contratos.

É para responder à questão recém proposta que Trebilcock ${ }^{8}$ serve-se da distinção entre monopólios situacionais e não situacionais ou, como ele denomina, "estruturais". Juízes, segundo ele, precisariam restringir-se a combater monopólios

7 COOTER, R.; ULEN, T. Law e economics. 4. ed. Boston: A. Wesley, 2004. p. 9; KAPLOW, L.; SHAVELL, S. Why the legal system is less efficient than the income tax in redistributing income. The Journal of Legal Studies, Oxford, v. 23, n. 2, p. 667-682, 1994.

8 TREBILCOCK, M. J. The limits of freedom of contract. Cambridge: Harvard, 1993. p. 93-96. 
da primeira espécie, ficando os da segunda a cargo de outros órgãos estatais especialmente designados para essa tarefa, os quais estariam mais aptos a lidar (quando comparados a órgãos judiciais adstritos a demandas individuais) com os efeitos mais abrangentes e "policêntricos" de monopólios estruturais. Opinião similar é sustentada por Craswell, ${ }^{9}$ para o qual, no entanto, a divisão de trabalho entre cortes e agências deveria se basear em um critério mais nuançado, pelo qual também se permita eventualmente às primeiras fazer frente a monopólios não situacionais - como no caso, por exemplo, em que os juízes possam comparar os preços de um produtor monopolista não circunstancial com os de um mercado similar, mas competitivo, existente em outro lugar.

Admitindo-se que a distinção entre monopólios situacionais e não situacionais seja mesmo relevante, de tal maneira que a intervenção judicial nos contratos deva, se não de todo, ao menos em grande medida ficar circunscrita aos primeiros, restaria estabelecer essa distinção mais claramente. Para Trebilcock, ${ }^{10}$ é característico dos monopólios não situacionais ou estruturais tratar-se aí de uma posição de vantagem não transitória, que se faz valer contra todos os parceiros e é anterior e independente das (ou "exógena" às) circunstâncias em que interagem os contratantes. Os casos de monopólio situacional, em contrapartida, são aqueles nos quais uma das partes, favorecida por uma particular conjuntura, obtém da outra um preço superior ao que ela mesma, ou outros em posição similar, costuma, geralmente, auferir.

Uma observação a fazer, entretanto, é que se os monopólios situacionais se definem pela excepcionalidade da vantagem que uma das partes detém sobre a outra, então é difícil imputar a esses monopólios o custo social anteriormente mencionado, o qual reside, lembre-se, não na maneira como o excedente contratual é repartido pelos contratantes, mas nas trocas que deixam de realizar-se em razão de preços artificialmente elevados. Isso porque o monopolista situacional é um cujos preços não se encontram, normalmente, acima do patamar competitivo

9 CRASWELL, R. Remedies when contracts lack consent: autonomy and institutional competence. Osgoode Hall Law Journal, Toronto, v. 33, n. 2, p. 209-235, 1995.

10 TREBILCOCK, M. J. The limits of freedom of contract. Cambridge: Harvard, 1993. p. 95. 
ou, pior ainda, alguém que não presta habitualmente o serviço em questão, como no caso do banhista a quem outro prestes a se afogar solicita ajuda. Logo, se o monopólio situacional é um do qual não decorre oferta aquém do que se verificaria sob concorrência, a razão para intervenção deixa de ser a eficiência (para a qual é indiferente, repita-se, o quanto do excedente contratual cabe a cada uma das partes), passando-se, assim, a ter que alegar a injustiça do contrato como motivo para a sua anulação ou revisão.

Outro ponto é o que diz respeito a casos de monopólio estrutural que geralmente estejam, por um motivo ou outro, fora do raio de ação de órgãos governamentais antitruste. Um desses casos é o do monopólio determinado pela infungibilidade de um bem, como o selo pelo qual o proprietário consiga um altíssimo preço de um colecionador desesperado. ${ }^{11}$ Outro é o do monopólio que se estabeleça graças à raridade do talento que alguém possua - por exemplo, um atleta ou artista. ${ }^{12}$ É simplesmente incomum, para não dizer inaudito, que órgãos estatais de defesa da concorrência se dediquem a combater monopólios como esses, e isso seja pelo fato de esses monopólios não trazerem consigo redução da oferta (caso dos monopólios da primeira espécie), seja por acreditar-se que as pessoas estejam moralmente autorizadas a tirar proveito de seus talentos, seja, finalmente, devido à reduzida repercussão desses casos. Qualquer que seja a explicação para a omissão dos órgãos governamentais, a questão é determinar se: (1) essa omissão é censurável, devendo o órgão regulador encarregado estender sua vigilância aos casos de monopólio não situacional sob exame; (2) esses casos hão de ter, excepcionalmente, o mesmo tratamento dos de monopólio situacional, isto é, sujeitar-se a normas de anulação e revisão contratual; ou (3) embora fora do alcance de agências governamentais, os contratos em pauta também não devem ser alvo de intervenção judicial, mas sim submeter-se à regra do pacta sunt servanda.

A proposta de limitar a aplicação de normas de anulação ou revisão contratual como a da lesão por premente necessidade aos casos de monopólio situacional

${ }_{11}$ TREBILCOCK, M. J. The limits of freedom of contract. Cambridge: Harvard, 1993. p. 87.

12 TREBILCOCK, M. J. The limits of freedom of contract. Cambridge: Harvard, 1993. p. 8788. 
merece, em síntese, os seguintes comentários. Primeiro, os casos de monopólio situacional são aqueles acerca dos quais, embora possa haver uma razão de justiça para corrigir o modo como as partes repartiram entre si o excedente contratual, falta a razão de eficiência pela qual se costuma defender o combate aos monopólios, a qual tem a ver não com os contratantes, mas com terceiros impedidos de consumir por preços acima do patamar competitivo. Segundo, seria preciso acrescentar à ideia de restringir o trabalho dos juízes aos monopólios situacionais alguma consideração a respeito de casos de monopólio estrutural habitualmente ignorados pelas agências antitruste, tais como os de monopólio determinado pela infungibilidade do bem demandado ou pela raridade do talento de um dos contratantes.

Parece ter um papel importante para as conclusões de Trebilcock o fato de haver, em muitos dos casos de monopólio situacional, um "preço de referência" com o qual se pode comparar o preço avençado, sendo esse preço de referência o que costuma ser demandado pelo bem em questão em circunstâncias "normais". ${ }^{13}$ No caso de um médico que ajuda a vítima de um mal súbito à beira de uma estrada, por exemplo, pode-se comparar o preço então havido pelo médico com o que ele mesmo costuma exigir, em outras circunstâncias, por serviço similar. Embora um critério baseado no preço de referência seja em alguma medida de fácil aplicação, tem-se de novo aí que observar que a disparidade entre o preço contratual e o preço de referência não oferece, em si mesma, uma razão de eficiência para a anulação ou revisão do contrato por lesão. ${ }^{14}$ Já no que concerne à repartição do excedente contratual segundo critérios de justiça, a discrepância em relação ao preço de referência revela apenas que, no contrato em questão, o excedente pode ter sido

\footnotetext{
${ }^{13}$ TREBILCOCK, M. J. The limits of freedom of contract. Cambridge: Harvard, 1993. p. 94.

${ }^{14}$ A observância do preço de referência é defendida por Craswell, o qual inclui, no entanto, entre as razões para intervenção judicial nos contratos razões de ordem distributiva. Além disso, no caso de Craswell, a existência de um preço de referência é relevante apenas devido à facilidade com que o critério baseado nesse preço pode ser aplicado pelos juízes, e não para distinguir os casos de monopólio a serem combatidos dos que devam ser tolerados. À falta de um preço de referência, segundo Craswell, a supervisão de monopólios deve caber a agências especialmente incumbidas dessa missão. CRASWELL, R. Remedies when contracts lack consent: autonomy and institutional competence. Osgoode Hall Law Journal, Toronto, v. 33, n. 2, p. 209-235, 1995.
} 
repartido de maneira diferente da usual..$^{15}$ Mas assim como não se deve, à falta de argumento, presumir justa a divisão do excedente que habitualmente ocorre, também não se pode, sem mais, ter como errônea a divisão levada a cabo sob monopólio situacional. Por fim, a menos que se consiga relacionar a ideia de preço de referência à de preço justo, ${ }^{16} \mathrm{o}$ fato de não haver preço de referência em casos de monopólio não situacional não impede que a repartição do excedente contratual ocorrida nesses casos seja condenável sob o ponto de vista da justiça.

\section{Lesão e custos de busca e prevenção}

Até aqui, considerou-se como custo social de contratos lesivos o infligido a terceiros que, em razão dos preços impostos por monopolistas, vejam-se "alijados do mercado", isto é, impedidos de contratar. A perda sofrida diz respeito aí, mais exatamente, ao excedente de contratos que deixam de ocorrer devido à falta de competição. Essa ideia sobre a ineficiência de contratos lesivos corresponde, segundo Tullock, ${ }^{17}$ ao ponto de vista predominante entre economistas até meados do século passado a respeito dos custos criados por monopólios. De acordo com o mesmo Tullock, ${ }^{18}$ esse ponto de vista fez com que o inconveniente dos monopólios fosse subestimado, já que, ao reduzir-se esse inconveniente ao "encolhimento" do mercado provocado por preços altos, ignorar-se-iam as perdas verificadas em razão da disputa dos agentes pelo poder monopolista.

${ }^{15}$ Usa-se aí o "pode" porque, sendo o excedente contratual determinado a partir dos preços de reserva das duas partes, não é de descartar que, dadas as peculiares circunstâncias em que um contrato é realizado, venham os preços de reserva a se apresentar de maneira também discrepante da usual, com a consequência de que a divisão do excedente contratual acabe se mostrando, em percentuais, similar à dos demais casos.

${ }^{16}$ Argumentos em defesa da ideia de preço justo podem ser encontrados em WERTHEIMER, A. Exploitation. Princeton: Princeton, 1996; BENSON, P. Abstract right and the possibility of a nondistributive conception of contract: Hegel and contemporary contract theory. Cardozo Law Review, New York, v. 10, n. 5-6, p. 1.077-1.198, 1989 e GORDLEY, J. Equality in exchange. California Law Review, Los Angeles, v. 69, n. 6, p. 1.587-1.656, 1981.

${ }_{17}$ TULLOCK, G. The welfare costs of tariffs, monopolies, and theft. Western Economic Journal, Fountain Valley, v. 5, n. 3, p. 224-232, 1967.

18 TULLOCK, G. The welfare costs of tariffs, monopolies, and theft. Western Economic Journal, Fountain Valley, v. 5, n. 3, p. 224-232, 1967. 
Tratando o monopólio como análogo ao roubo, Tullock ${ }^{19}$ afirma que além dos recursos expropriados dos consumidores por monopolistas, os quais, como recursos meramente transferidos, não influem sobre o tamanho do "bolo" (isto é, sobre o bem-estar global), há que se considerar os recursos despendidos pelos agentes para alcançar a posição de monopolista, bem como os de consumidores para se contrapor às investidas daqueles. Os recursos desperdiçados são aí não apenas os empregados pelos que venham, de fato, a se tornar monopolistas, mas por todos os que tentem conquistar tal status, já que, para maximizar seus ganhos, todo empresário deveria esforçar-se para obter monopólio até o ponto em que o custo marginal de tal esforço seja igual ao seu benefício marginal esperado (o benefício do monopólio, multiplicado pela probabilidade de esse monopólio ser conseguido). De modo similar, consumidores maximizadores de utilidade tomariam medidas para prevenir o surgimento de monopólios até que o custo marginal dessas medidas coincida com seu benefício marginal esperado (o benefício da prevenção ao monopólio, multiplicado pela probabilidade de que as referidas medidas preventivas surtam efeito).

A ideia de que a disputa pela posição monopolista acarrete perdas relacionadas tanto à atividade dos que perseguem tal posição como à daqueles que tratam de proteger-se contra os primeiros é também encontrada na análise econômica dos contratos, a qual, em linhas gerais, lida aí com o que Trebilcock ${ }^{20}$ designa como monopólio situacional. Um exemplo recente de análise na qual os custos decorrentes de busca e prevenção são considerados é propiciado por Shavell. ${ }^{21}$

O trabalho de Shavell é dedicado aos casos de holdup contratual, definidos como aqueles em que uma das partes de um contrato, por "relevante necessidade" (substantial need) rendese a uma exigência "bastante desvantajosa" (very disadvantageous) da outra. O holdup pode ocorrer tanto entre partes que ainda não contrataram, como no caso do eletricista que, no último dia do ano, estipula preço muito acima do usual para um reparo sem o qual o jantar de ano-novo de um restaurante

19 TULLOCK, G. The welfare costs of tariffs, monopolies, and theft. Western Economic Journal, Fountain Valley, v. 5, n. 3, p. 224-232, 1967.

${ }^{20}$ TREBILCOCK, M. J. The limits of freedom of contract. Cambridge: Harvard, 1993.

${ }^{21}$ SHAVELL, S. Contractual holdup and legal intervention. The Journal of Legal Studies, Oxford. v. 36, n. 2, p. 325-354, 2007. 
não poderá ser servido, como em relações contratuais já estabelecidas, de que é exemplo o caso de um ator de seriado de TV que, para prosseguir com as gravações, exige remuneração duas vezes maior do que a avençada originalmente.

Como é praxe em análises guiadas pelo critério da eficiência, Shavell não dispensa maior atenção à repartição do excedente contratual nos casos de holdup, a não ser para presumir que a porção desse excedente apropriada pela contraparte seja substancial. ${ }^{22}$ Ao invés de se referir aos recursos que são expropriados do contratante em necessidade pela outra parte, os inconvenientes do holdup consistiriam nos seguintes: ${ }^{23}$ (1) potenciais contratantes podem empreender esforços para engendrar situações de necessidade, sendo tais esforços socialmente indesejáveis porque, além de custosos em si mesmo (custos de busca), podem também dar lugar a outros custos (como o custo da perda para a vítima, caso ela se recuse a ser ajudada ou a ajuda se mostre ineficaz); (2) potenciais vítimas podem incorrer em custos para reduzir a probabilidade de ocorrência do holdup (custos de prevenção); (3) potenciais vítimas podem também abster-se de realizar investimentos que as deixem mais vulneráveis ao holdup (custos de investimento); e (4) para potenciais vítimas com aversão ao risco, o risco do holdup é em si mesmo, e independentemente de a situação de necessidade vir mesmo a se verificar, um custo a ser suportado (custos do risco). Por outro lado, o alto preço obtido por um dos contratantes em casos de holdup confere um incentivo a que pessoas em situação de necessidade sejam socorridas e poupadas de uma perda iminente, mostrando-se, por essa razão, socialmente desejável. ${ }^{24}$

A solução proposta por Shavell para o holdup contratual baseia-se na distinção entre os casos em que a situação de necessidade é engendrada pelo contratante beneficiado e aqueles em que isso não ocorre. ${ }^{25}$ Para os casos da primeira espécie,

${ }^{22}$ SHAVELL, S. Contractual holdup and legal intervention. The Journal of Legal Studies, Oxford. v. 36, n. 2, p. 325-354, 2007. p. 330.

${ }^{23}$ SHAVELL, S. Contractual holdup and legal intervention. The Journal of Legal Studies, Oxford. v. 36, n. 2, p. 325-354, 2007. p. 330-331.

${ }^{24}$ SHAVELL, S. Contractual holdup and legal intervention. The Journal of Legal Studies, Oxford. v. 36, n. 2, p. 325-354, 2007. p. 331.

${ }^{25}$ SHAVELL, S. Contractual holdup and legal intervention. The Journal of Legal Studies, Oxford. v. 36, n. 2, p. 325-354, 2007. p. 331-333. 
Shavell preconiza a anulação do contrato como medida de desestímulo a atividades destinadas a forjar situações de necessidade. Já para os casos da segunda espécie, em que a situação de necessidade de um dos contratantes não pode ser atribuída ao outro, a solução mais adequada seria a do controle de preços, realizado seja mediante a revisão de contratos, seja pela anulação de contratos com preço superior ao ótimo. Como preço ótimo considerar-se-ia aí o que induza a minimizar os custos sociais envolvidos - o custo da perda para a vítima, caso o socorro não ocorra ou não seja bem sucedido, bem como o da prevenção e o do risco (para potenciais vítimas) e o da ajuda para o contratante beneficiado. A ideia, em outras palavras, é a de estipular um preço que proporcione a potenciais "salvadores" o incentivo a engajarem-se em atividades de busca e resgate, mas apenas à medida que o exercício dessas atividades seja o meio adequado de minimizar os custos em jogo. Embora reconheça que a determinação do preço ótimo é tarefa para a qual os juízes nem sempre dispõem de informação suficiente e que o erro judicial a esse respeito pode impedir a realização de contratos socialmente benéficos, ${ }^{26}$ Shavell se mostra favorável à intervenção estatal em casos de holdup (com limites de preço estabelecidos generosamente, de maneira a minimizar os custos de decisões judiciais equivocadas), sugerindo acrescentar às razões standard para a intervenção nos contratos - assimetria informativa e externalidades - uma terceira relacionada ao holdup. ${ }^{27}$

Além de apresentar semelhanças com a análise dos custos sociais de monopólios em Tullock ${ }^{28}$ e Posner, ${ }^{29} \mathrm{o}$ inventário dos custos sociais do holdup feito por Shavell tem antecedentes na análise econômica dos contratos. Tratando de contratos feitos para salvar uma pessoa (ou seus bens) de perigo, Landes e Posner ${ }^{30}$ também se referem à conveniência de conciliar o incentivo ao socorro com a redução

${ }^{26}$ SHAVELL, S. Contractual holdup and legal intervention. The Journal of Legal Studies, Oxford. v. 36, n. 2, p. 325-354, 2007. p. 333-334.

${ }^{27}$ SHAVELL, S. Contractual holdup and legal intervention. The Journal of Legal Studies, Oxford. v. 36, n. 2, p. 325-354, 2007. p. 347.

${ }^{28}$ TULLOCK, G. The welfare costs of tariffs, monopolies, and theft. Western Economic Journal, Fountain Valley, v. 5, n. 3, p. 224-232, 1967.

${ }^{29}$ POSNER, R. A. The social costs of monopoly and regulation. The Journal of Political Economy, Illinois, v. 83, n. 4, p. 807-828, 1975.

${ }^{30}$ LANDES, W. M.; POSNER, R. A. Salvors, finders, good samaritans and other rescuers: An economic study of law and altruism. The Journal of Legal Studies, Oxford, v. 7, n. 1, p. 83-128, 1978. 
aos custos de prevenção, já que uma recompensa exagerada aos que prestam ajuda pode elevar as despesas com precaução feitas por potenciais vítimas a um patamar superior ao desejável. Como os casos que examinam são, todavia, aqueles em que uma das partes não contribui para a situação de apuros da outra, Landes e Posner não se valem da distinção entre situações de necessidade engendradas (SNE) e não engendradas (SNN) feita por Shavell. ${ }^{31}$ Quanto aos casos de holdup em que se modifica em favor de uma das partes contrato anteriormente celebrado (sem que haja uma alteração dos custos de cumprimento a justificar tal modificação), Aivazian, Trebilcock e Penny ${ }^{32}$ defendem que a lei se oponha à modificação a fim de poupar custos de prevenção de potenciais vítimas, que eles descrevem como custos de transação ou, mais exatamente, como custos para a confecção de cláusulas contratuais que impeçam o posterior holdup. Outros trabalhos a tratar da relação entre intervenção judicial e incentivos a potenciais salvadores e vítimas são os de Cserne e Szalai, ${ }^{33}$ Esposto $^{34}$ e Buckley. ${ }^{35}$

É de se ressalvar que nem todos os autores citados se mostram favoráveis à intervenção judicial nos contratos. As divergências, no entanto, provêm menos da ideia dos custos a considerar do que das diversas escolhas metodológicas à base das quais a análise desses custos tem lugar. No caso de Esposto, ${ }^{36}$ parte-se da premissa de que suportar as ocasionais perdas advindas de situações de necessidade é um risco contra o qual a potencial vítima pode precaver-se ex ante, inclusive mediante contrato (por exemplo, o dono do navio que, contando com a eventual necessidade,

${ }^{31}$ SHAVELL, S. Contractual holdup and legal intervention. The Journal of Legal Studies, Oxford. v. 36, n. 2, p. 325-354, 2007.

32 AIVAZIAN, V. A.; TREBILCOCK, M. J.; PENNY, M. The law of contractual modifications: the uncertain quest for a bench mark of enforceability. Osgoode Hall Law Journal, Toronto, v. 22, n. 2, p. 173-212, 1984.

${ }^{33}$ CSERNE, P.; SZALAI, A. On the necessity of necessity: an economic analysis of contracts concluded in a situation of need. Silesian Journal of Legal Studies, Bankowa, v. 2, p. 11-25, 2010.

${ }^{34}$ ESPOSTO, A. G. Contracts, necessity and ex ante optimality. European Journal of Law and Economics, New York, v. 9, n. 2, p. 145-156, 1999.

${ }^{35}$ BUCKLEY, F. H. Three theories of substantial fairness. Hofstra Law Review, New York, v. 19, p. 33-66, 1990.

${ }^{36}$ ESPOSTO, A. G. Contracts, necessity and ex ante optimality. European Journal of Law and Economics, New York, v. 9, n. 2, p. 145-156, 1999. 
acerta antecipadamente serviço de resgate). A conclusão de Esposto é a de que a intervenção estatal para anulação ou revisão de contratos celebrados em situação de necessidade elimina uma das alternativas com que se deparam potenciais vítimas, a que consiste, justamente, em sujeitar-se ao risco do holdup e suas consequências. $\mathrm{O}$ problema é que, do ponto de vista dos envolvidos, incluindo aí a vítima, a sujeição ao risco pode ser, ex ante, a melhor das alternativas, de maneira que, ao intervir, a lei impediria as partes de minimizar elas mesmas os custos a que se sujeitam. A probabilidade de que a aplicação de uma regra de livre mercado ou pacta sunt servanda seja, ex ante, a solução ótima aumenta, segundo Esposto, quando os custos em que a potencial vítima tenha de incorrer para precaver-se não sejam contínuos e o preço dos contratos realizados em situação de necessidade seja limitado por normas sociais.

Considerar-se-á mais detidamente aqui a solução defendida por Shavell ${ }^{37}$ para os casos de holdup ou lesão por premente necessidade. Como já observado, crucial para as conclusões de Shavell é, antes de tudo, a distinção entre as situações de necessidade engendradas (SNE) pela contraparte e as que não o são (SNN). Essa distinção é decisiva para a análise porque, de acordo com Shavell, os casos da primeira espécie devem ser resolvidos mediante anulação do contrato, enquanto que os da segunda podem demandar apenas abatimento de preço (isto é, revisão) ou, na pior das hipóteses, anulação dos contratos cujo preço seja superior ao ótimo. Exemplos do primeiro gênero (situações de necessidade engendradas) são o da doação feita sob ameaça de afogamento ${ }^{38}$ e o de uma construtora que inicia obra com o uso de técnica mais cara e desconhecida por outros construtores, para então, em meio aos trabalhos, exigir aumento substancial do preço. Exemplos de situação de necessidade não engendrada são os do eletricista chamado com urgência a prestar serviço a restaurante no último dia do ano e o do resgate de um navio prestes a afundar.

\footnotetext{
${ }^{37}$ SHAVELL, S. Contractual holdup and legal intervention. The Journal of Legal Studies, Oxford. v. 36, n. 2, p. 325-354, 2007.

${ }^{38}$ Como o exemplo deixa claro, entre as situações de necessidade engendrada estão algumas que, no direito brasileiro, seriam provavelmente reconhecidas como de coação. A análise de Shavell não se limita, portanto, ao que entre nós se designaria como lesão contratual, oferecendo também uma justificativa para a anulação de contratos por outras causas.
} 
Convém observar aí como a definição que Shavell oferece de uma situação de necessidade é pouco detalhada. Quando essa definição de fato aparece - já que, na parte introdutória do artigo, Shavell limita-se a exemplos ${ }^{39}-$, diz-se que a situação de necessidade é uma na qual a vítima se encontra na iminência de sofrer uma perda (loss), a qual, no entanto, pode ser evitada mediante ajuda da outra parte. ${ }^{40}$ Dependendo, porém, do sentido que se empreste à palavra "perda", todo o contrato que se mostre satisfatório para ao menos uma das partes é (para a parte em questão) um contrato feito em situação de necessidade, já que, sem o contrato, ter-se-ia uma perda correspondente a não realização d o ganho que o contrato é capaz de proporcionar. Em relação a isso, uma maneira de reduzir o conceito de perda e, em consequência, limitar o rol de contratos firmados em situação de necessidade seria tratar como perda apenas uma piora na situação de um dos contratantes, de modo que a necessidade ficaria caracterizada apenas quando, sem o contrato (como no exemplo do navio em apuros), um dos contratantes acabe em situação pior do que aquela na qual atualmente se encontra. Nem todos os casos examinados por Shavell são, no entanto, de contratos pelos quais uma perda nesse último sentido é evitada: no caso do serviço prestado pelo eletricista a um restaurante, a falta do serviço privará o restaurante dos prováveis ganhos com o jantar de ano-novo, mas não o deixará em estado pior do que o anterior à realização do contrato, quando os referidos ganhos ainda não se verificaram. Outra alternativa, por fim, seria dizer que a perda caracterizadora da situação de necessidade é aquela relacionada à inexistência de outros potenciais contratantes, de tal modo que a situação de necessidade se deva ao fato de que, sem a outra, uma das partes não obterá a vantagem propiciada pelo contrato, sofrendo aí, nesse sentido, uma perda (a qual pode traduzir-se tanto por uma piora em relação ao status quo como pela não ocorrência de uma melhora). A consequência de entender-se perda nesse último sentido, no entanto, é que, em casos de monopólio bilateral - em que cada um dos envolvidos é o único potencial parceiro do outro -, ambas as partes se encontrariam, ao contratar, em situação de necessidade. Dito isso, deve-se ponderar que as dificuldades enfrentadas para definir perda e, por conseguinte, situação de necessidade têm para análise de Shavell

${ }^{39}$ SHAVELL, S. Contractual holdup and legal intervention. The Journal of Legal Studies, Oxford. v. 36, n. 2, p. 325-354, 2007. p. 326.

${ }^{40}$ SHAVELL, S. Contractual holdup and legal intervention. The Journal of Legal Studies, Oxford. v. 36, n. 2, p. 325-354, 2007. p. 329. 
uma importância secundária, já que essa análise se ampara, mais do que na ideia de situação de necessidade em si, naquilo que a antecede e, em particular, na distinção entre SNE e SNN. ${ }^{41}$

A anulação do contrato é a medida recomendada a fim de eliminar qualquer incentivo a forjar situações de necessidade, já que a atividade destinada a ensejar uma situação assim é socialmente custosa, constituindo, pois, um desperdício. ${ }^{42}$ Em relação a tal afirmação, faz-se indispensável examinar duas questões, não forçosamente independentes uma da outra. Uma (1) é a de determinar como se estabelece a diferença entre SNE e SNN, e a outra (2) a de saber se toda a atividade destinada a criar situações de necessidade é mesmo socialmente indesejável e, por conseguinte, corrobora a conclusão de Shavell quanto ao diverso tratamento a dispensar a um e outro caso.

Quanto a (1), parece de descartar a ideia de que se trate, em SNE, apenas de uma relação de causalidade (no sentido de uma causalidade natural ou but for) entre a conduta de um dos contratantes e a situação de necessidade em que encontra o outro. Uma relação de causalidade assim se verifica no caso do contrato feito sob ameaça de afogamento, mas também (possivelmente) no do restaurante (que Shavell cita como exemplo de SNN), já que a omissão do eletricista (que poderia ter-se apresentado para a realização do serviço antecipadamente) é também causa, no sentido referido, do dano que a outra parte se encontra na iminência de sofrer. Assim, se a diferença entre SNE e SNN imaginada por Shavell apoia-se em uma relação de causalidade, essa é uma na qual se juntam, à ideia de causa natural, critérios de imputação ou responsabilidade ${ }^{43}$ como ao dizer-se que o autor da ameaça

${ }^{41}$ Que o conceito de "necessidade" seja secundário para uma análise econômica da lesão é algo explicitamente defendido por Cserne e Szalai, ao invés de tratar a situação de necessidade de um dos contratantes como requisito para a intervenção judicial nos contratos, esses autores propõem considerar como de necessidade aqueles casos em que a análise demonstre ser conveniente a intervenção, conveniência, essa, a ser avaliada pelos custos envolvidos, e não à base da situação das partes ao contratar. CSERNE, P.; SZALAI, A. On the necessity of necessity: an economic analysis of contracts concluded in a situation of need. Silesian Journal of Legal Studies, Bankowa, v. 2, p. 11-25, 2010.

${ }^{42}$ SHAVELL, S. Contractual holdup and legal intervention. The Journal of Legal Studies, Oxford. v. 36, n. 2, p. 325-354, 2007.

${ }^{43}$ HART, H. L. A.; HONORÉ, T. Causation in the law. 2. ed. Oxford: Clarendon, 1985. 
estava obrigado a abster-se dela, mas que o eletricista, em contrapartida, não era devedor, à falta de um contrato, da prestação do serviço ao restaurante.

Outra possibilidade é responder à questão (1) com base em um critério de custo social. A ideia aí seria designar como SNE as situações em que a atividade do contratante beneficiado é socialmente indesejável, isto é, dá lugar a um custo social, e como SNN aquelas em que isso não acontece. Assim, retornando aos exemplos, dir-se-ia que o contrato feito sob ameaça de afogamento decorre de uma SNE porque a atividade do autor da ameaça inflige um custo à sociedade, enquanto que o contrato feito pelo restaurante se baseia em uma SNN porque, diferentemente, à omissão anterior do eletricista não corresponde custo social algum.

A solução sugerida no parágrafo anterior leva a que a resposta à questão (2) seja afirmativa por definição: qualquer atividade causadora de SNE é socialmente custosa porque SNE são as que se verificam em consequência de atividades assim. O decisivo, então, seria determinar quando uma atividade impõe custo à sociedade, uma questão acerca da qual Shavell é pouco explícito, já que se limita a afirmar que o ato pelo qual uma situação de necessidade é criada é "custoso em si mesmo" (costly in itself), ${ }^{44}$ não deixando claro em que esse custo consiste. Compare-se isso com a asserção análoga, mas muito mais cautelosa, feita por Posner ${ }^{45}$ sobre os custos sociais de monopólios. Esse último elege como pressuposto o de que atividades destinadas à obtenção ou preservação da posição monopolista não possuem qualquer efeito socialmente benéfico, ${ }^{46}$ acrescentando tratar-se aí, porém, de uma pressuposição feita apenas para simplificação, já que muitos dos esforços despendidos por agentes para lograr monopólio seriam, sim, valiosos, de tal maneira que as conclusões da análise teriam seu alcance limitado, segundo o próprio Posner, aos casos em que o estratagema usado para a perseguição do monopólio

${ }^{44}$ SHAVELL, S. Contractual holdup and legal intervention. The Journal of Legal Studies, Oxford. v. 36, n. 2, p. 325-354, 2007. p. 330.

${ }^{45}$ POSNER, R. A. The social costs of monopoly and regulation. The Journal of Political Economy, Illinois, v. 83, n. 4, p. 807-828, 1975.

${ }^{46}$ POSNER, R. A. The social costs of monopoly and regulation. The Journal of Political Economy, Illinois, v. 83, n. 4, p. 807-828, 1975. 
tenha pouco ou nenhum valor social. ${ }^{47}$ Tampouco há, no autor por último citado, uma explicação sobre o que leva a atribuir à atividade de potenciais monopolistas um efeito socialmente desejável ou a respeito do que, em contrapartida, permite dizer que tal atividade imponha apenas custos, muito embora alguns exemplos sejam oferecidos. Assim, ele pondera que a tentativa de conquistar monopólio é em alguma medida socialmente bem-vinda quando se faça por meio da inovação ou da redução de custos e preços, enquanto seriam casos de atividade eminentemente nociva os das destinadas à formação de cartel e à imposição de tarifas para importação ou outras medidas legais protetivas. ${ }^{48}$

É possível que o aparente desleixo com que os conceitos de "custo" e "benefício" são por vezes tratados seja uma simples consequência do seu uso abrangente pela análise econômica e do fato de que, na análise do holdup contratual ou dos monopólios, esse uso não destoe do que geralmente acontece. Admita-se, então, que os conceitos de "custo" e "benefício" estejam ambos relacionados à disposição a pagar (isto é, ao preço de reserva), de tal maneira que benefício seja algo pelo que alguém esteja disposto a pagar uma soma qualquer, ainda que ínfima, e custo, inversamente, algo que se queira evitar mediante o desembolso de certa quantia. Falar-se-ia, assim, em "benefício social" em relação a tudo aquilo cujo benefício seja superior ao custo, isto é, em relação a algo pelo que a soma do que se esteja disposto a pagar em uma sociedade seja superior à disposição a pagar inversa. Uma atividade seria socialmente benéfica, por exemplo, se o montante total do que se queira pagar por ela seja $\mathrm{R} \$ 1.000 .000,00$, e o montante do que se queira pagar para evitá-la igual a $\mathrm{R} \$ 800.000,00$. “Custo social”, em contrapartida, possuiria tudo aquilo cujos custos somados sejam superiores aos benefícios.

Um desafio a enfrentar para aplicação de um critério baseado na disposição a pagar é o de aferir essa disposição. Naquilo que se refere propriamente a relações contratuais, a realização do contrato constitui, como visto acima, um indício acerca da disposição a pagar ou preço de reserva das partes - se $A$ vendeu para $B$ um

${ }^{47}$ POSNER, R. A. The social costs of monopoly and regulation. The Journal of Political Economy, Illinois, v. 83, n. 4, p. 807-828, 1975.

${ }^{48}$ POSNER, R. A. The social costs of monopoly and regulation. The Journal of Political Economy, Illinois, v. 83, n. 4, p. 807-828, 1975. 
imóvel por R \$55.000,00, isso sugere que o preço de reserva do primeiro é igual ou inferior a essa quantia, que também deve ser igual ou superior ao preço de reserva do segundo. Da falta de um contrato, entretanto, pode-se apenas inferir uma relação entre os preços de reserva das partes - se $A$ e $B$ não chegam a um acordo para a venda da casa, isso sugere que o preço de reserva de $A$ é superior ao de $B$ - uma inferência sujeita, no entanto, à ressalva de que o contrato pode não ter ocorrido por razões independentes da disposição a pagar dos envolvidos (por exemplo, em razão de custos de transação). Quando se trata, pois, de relações não contratuais, a disposição a pagar tem que ser descoberta por outros meios, tais como os de que fazem uso análises de custo e benefício. ${ }^{49}$ Por fim, e alternativamente, pode-se suprir a falta de informação por meio de suposições.

É importante observar como a análise dos custos sociais do holdup tem de basear-se, em grande medida, em disposições a pagar que não são reveladas por meio de contratos. Considerem-se os exemplos de Shavell de situações de necessidade engendradas (SNE) em que, segundo ele, a atividade pela qual a situação de necessidade é criada, por tratar-se de atividade socialmente danosa, deve ser evitada mediante a anulação do contrato. Um dos exemplos, como já referido, é o de alguém constrangido a realizar doação devido a ameaça de afogamento, enquanto o outro é o de uma construtora que, em meio a uma obra para a qual foi empregada técnica incomum e mais cara, aproveita-se do despreparo de outras construtoras para dar continuidade aos trabalhos a fim de exigir do outro contratante um aumento considerável do preço. Nesses dois exemplos, as atividades pelas quais se engendram as situações de necessidade são, respectivamente, a ameaça de afogamento (feita à beira de um rio e com uma corda amarrada ao pescoço da vítima) e o uso de técnica não usual para a feitura da obra. Trata-se, em ambos, de atividades capazes de ensejar um contrato, mas não de atividades sobre as quais haja um contrato e, por conseguinte, de atividades sobre as quais algum dos envolvidos tenha manifestado sua disposição a pagar: não se sabe o quanto a vítima da ameaça de afogamento teria pago para não se sujeitar a tal ameaça, nem quanto o dono da obra pagaria à construtora para que realizasse essa última segundo as

${ }^{49}$ Cf., p. ex., BOARDMAN, A. et al. Cost-benefit analysis: concepts and practice. 4. ed. Nova Iorque: Prentice-Hall, 2010. 
técnicas usuais. À medida, pois, que a análise de custos atrele esses últimos a preços de reserva, a afirmação de que as atividades dos exemplos dão lugar a custos sociais talvez tenha de apoiar-se em suposições, a começar pela de que a vítima da ameaça pagaria algo para evitá-la, e a de que o empreitante estaria, também, disposto a pagar para que a construtora tivesse usado técnica de construção mais corriqueira. Além disso, pode ser útil supor que o benefício proporcionado pelas mesmas atividades se resuma à vantagem que, em decorrência delas, seja auferida no contrato posteriormente feito - em outras palavras, que a ameaça não tenha para seu autor nenhum valor que não o do benefício esperado do futuro contrato, o mesmo valendo para a técnica de construção. Finalmente, pode-se que presumir que as atividades em questão não possuam valor para mais ninguém, isto é, que ninguém, além da parte beneficiada pelo contrato, esteja disposto a pagar para que as referidas atividades ocorram. É somente à base de todas essas suposições que se pode afirmar com segurança serem os atos desencadeadores das situações de necessidade nos dois exemplos socialmente indesejáveis, já que a todo benefício proporcionado por esses atos (a porção do excedente contratual ${ }^{50}$ que, graças a eles, é apropriada por uma das partes) contrapor-se-ia um custo de mesma magnitude (o custo da expropriação desse excedente para a parte contrária) ao qual seriam, ainda, acrescidos outros custos, tais como o da realização da ameaça para a vítima e seu autor e o do uso da técnica incomum pelo empreiteiro.

Esse cômputo de benefícios e custos feito não segundo preferências reveladas pela decisão de contratar, mas à base de suposições sobre quais seriam essas preferências caso certos contratos tivessem lugar, impõe-se, também, à análise das situações de necessidade não engendradas, nas quais, ao invés de coibir a atividade pela qual uma das partes reduz a outra a uma situação de necessidade, trata-se de minimizar custos de variadas ordens, incluindo-se aí, além do custo a ser suportado pela parte em situação de necessidade caso o contrato não se realize, os custos de busca com que arcam potenciais “salvadores" e os de prevenção, investimento e

\footnotetext{
${ }^{50} \mathrm{~A}$ análise não se altera significativamente em casos nos quais, como talvez ocorra com a doação feita sob ameaça de afogamento, não haja excedente contratual algum. Apenas é preciso considerar que, se os recursos transferidos contratualmente possuem mais valor para a parte de quem eles são expropriados, o benefício auferido pela outra é inferior ao custo que o contrato impõe à primeira.
} 
risco para potenciais vítimas. Para a minimização de todos esses custos, recomenda-se, como visto, a intervenção judicial para limitação do preço contratual, o qual, idealmente, deveria ser aquele pelo qual as partes sejam incentivadas a combinar otimamente (isto é, de maneira a diminuir ao máximo) os diferentes custos em jogo. Como o próprio Shavell admite, ${ }^{51}$ todavia, faltam ao Estado informações para definir esse limite de preço com exatidão. A fim de simplificar a tarefa dos órgãos judiciais, ele sugere avaliar, em cada caso, quais “fatores” (isto é, espécies de custos) parecem mais relevantes, para, à luz de tal avaliação, estimar o preço ótimo ${ }^{52}$. Por exemplo, em casos nos quais os custos de busca pareçam pouco consideráveis, não seria preciso estipular um preço muito alto para incentivar potenciais salvadores a incorrer nesses custos e prevenir, com isso, a perda que a outra parte encontra-se na iminência de sofrer; em casos nos quais essa perda corresponda à porção significativa do patrimônio da vítima, o custo do risco respectivo tem de ser levado em conta, mas já não quando essa mesma perda não se mostre tão ruinosa.

Para chegar, de acordo com prescrições assim, a uma estimativa sobre o preço ótimo, é também necessário, finalmente, contar com outras suposições sobre preferências além daquela segundo a qual o custo de cada real despendido em prevenção por potenciais vítimas equivalha ao de cada real invertido em salvamento pela outra parte (suposição essa implícita no critério da disposição a pagar). Além de tal suposição, que aconselha a permitir ao contratante beneficiado a apropriação de boa parcela ou até da totalidade do excedente contratual nos casos em que as despesas com salvamento sejam inferiores às que teria de fazer a própria vítima para precaver-se, são imprescindíveis outras a respeito do custo da perda para a vítima, o qual é em parte, mas não necessariamente de todo, revelado pelo preço contratual, e que pode consistir em um custo apenas para a vítima ou também para outras pessoas (cuja disposição a pagar para evitar a referida perda também precisaria, então, ser levada em conta). As considerações feitas nos últimos parágrafos não se destinam, ressalte-se, a invalidar as conclusões da análise econômica da lesão contratual, mas, simplesmente, a trazer à luz alguns dos pressupostos, nem

${ }^{51}$ SHAVELL, S. Contractual holdup and legal intervention. The Journal of Legal Studies, Oxford. v. 36, n. 2, p. 325-354, 2007.

52 SHAVELL, S. Contractual holdup and legal intervention. The Journal of Legal Studies, Oxford. v. 36, n. 2, p. 325-354, 2007. 
sempre suficientemente explicitados, nos quais essas conclusões se baseiam. O que se nota, em resumo, é que embora a distinção entre SNE e SNN estabelecida por Shavell possa se apoiar em uma relação de causalidade independente da natureza (socialmente desejável ou indesejável) da atividade a que a situação de necessidade seja imputada, essa relação de causalidade, devido ao seu conteúdo normativo, não é um "dado", antes tendo de ser construída pela análise mesma. Além disso, para que se considere a atividade ensejadora da situação de necessidade (ou holdup) socialmente custosa - ou mesmo no caso em que se pretenda, como foi aventado, definir como atividade causadora da referida situação apenas aquela cujo benefício à sociedade seja inferior ao custo -, algum critério sobre como custos e benefícios hão de ser mensurados tem de ser postulado. Essa última observação é assaz conhecida por todo aquele que esteja minimamente familiarizado com a crítica à Economia como ciência do bem-estar social, ${ }^{53}$ sendo quando muito de salientar aí que, na análise do custo social da lesão contratual, alguns dos custos computados (entre eles, os custos da atividade ensejadora da situação de necessidade) são custos que não se revelam em contratos nos quais as partes manifestem sua disposição a pagar por algo (ou caso se queira, suas preferências). Tanto quanto se atrelem a preços de reserva ou preferências não descortinados por uma decisão de contratar, esses custos podem, então, acabar calculados a partir de suposições, essas também nem sempre suficientemente explicitadas, sobre a disposição a pagar dos envolvidos.

É claro que suposições sobre o custo social de certas atividades não são, em geral, um puro fruto da imaginação, antes correspondendo a ideias de valor bastante difundidas. Não deixa, contudo, de ser parte do trabalho de "auto-reflexão" a que pode se dedicar a análise ${ }^{54} \mathrm{o}$ alertar-se para o fato de que as suposições em questão podem sujeitar-se à influência de preferências que são, antes de mais nada, do investigador mesmo. No caso do contrato de empreitada, Shavell ${ }^{55}$ apresenta como exemplo de atividade socialmente danosa o uso pela construtora de uma técnica "mais cara do que preciso". Que essa atividade seja desprovida de valor (a

\footnotetext{
${ }^{53}$ Cf., p. ex., DWORKIN, R. A matter of principle. Cambridge: Harvard, 1985. p. 237-266.

${ }^{54}$ Cf., sobre isso, BOURDIEU, P. Méditations pascaliennes. Paris: Le Seuil, 1997.

${ }^{55}$ SHAVELL, S. Contractual holdup and legal intervention. The Journal of Legal Studies, Oxford. v. 36, n. 2, p. 325-354, 2007.
} 
não ser pela vantagem que permite à construtora extrair da outra parte depois de iniciada a obra) é algo que se afirma com base na suposição de que ninguém esteja disposto a pagar mais pelo emprego de uma técnica que, além de consumir mais recursos, mostra-se "desnecessária”, isto é, sem qualquer efeito sobre o resultado, a “obra em si”. Enquanto, de um lado, essa suposição de uma indisposição a pagar pelo que sirva à mera ostentação, a qual trata, pois, como supérfluo tudo aquilo que seja desprovido de "valor de uso", parece ser em grande medida correta para muitas sociedades atuais, de outro é de se imaginar que a condenação ao que se vê aí como "esbanjamento" seja condizente, antes de mais nada, com as preferências de um economista como Shavell.

Ao incorporar ideias de valor em alguma medida disseminadas, a análise dos custos do holdup contratual termina por conferir validade a essas ideias. $\mathrm{O}$ curioso é notar, em consequência, como a carga valorativa da análise transcende seus pressupostos mais explícitos (por exemplo, a eficiência) e as conclusões que, à base desses pressupostos, pontualmente se obtenham (por exemplo, sobre a intervenção estatal nos contratos feitos em situação de necessidade). Esses pressupostos e conclusões, porque mais perceptíveis, estão também mais sujeitos a encontrar resistência do que certas preferências que, implícitas, mostram-se, ao contrário, e por isso mesmo, mais renitentes.

\section{Considerações finais}

Este artigo dispôs-se a examinar criticamente a análise econômica dos contratos realizados sob premente necessidade, uma das espécies de contratos lesivos previstas pelo art. 157 do Código Civil. Sua primeira parte girou em torno do conceito de excedente contratual e da distinção entre monopólios situacionais e não situacionais (ou estruturais), crucial para a análise de Trebilcock sobre os contratos realizados em situação de necessidade. Viu-se que a conclusão que essa distinção embasa - a de que a anulação ou revisão de contratos por lesão deve cingir-se aos casos de monopólio situacional - não é condizente com uma das premissas da análise, segundo a qual o que importa, nos contratos, não é a maneira como o ganho deles resultante é repartido entre as partes, mas sim a realização, pura e simples, 
desse ganho, a qual deixa de verificar-se sempre que, devido à posição monopolista, a oferta de certo bem seja reduzida.

$\mathrm{Na}$ segunda parte, tratou-se da análise econômica dos contratos lesivos como análise não do contrato em si ou das circunstâncias em que ele é celebrado (de que é sintoma a indefinição sobre o conceito de necessidade, bem como sua relativa desimportância), mas dos custos que por meio desse contrato, e do preço que para ele se estabeleça, possam ser reduzidos. Fez-se aí, em primeiro lugar, a crítica da distinção proposta por Shavell entre situações de necessidade engendradas (SNE) e situações de necessidade não engendradas (SNN). Quanto às primeiras, a respeito das quais, segundo o mesmo Shavell, o recomendado seria negar validade ao contrato a fim de desestimular a atividade da qual a situação de necessidade, ou holdup, é resultado, viu-se que a ideia de uma atividade causadora de uma situação de necessidade dificilmente é aproveitável para fins legais se não acompanhada de algum critério pelo qual se possa, entre os inúmeros fatos sem os quais a situação de necessidade não teria ocorrido, imputar a um (ou alguns) tal situação. Por outro lado, caso se queira considerar como atividade ensejadora da situação de necessidade toda aquela que se mostre socialmente lesiva, faz-se imprescindível uma ponderação dos custos e benefícios de atividades pregressas ao contrato que, ao guiar-se pela disposição a pagar por essas mesmas atividades, tenha como base preferências que são, em grande medida, ao invés de evidenciadas pelas partes envolvidas, tão-somente supostas. Sujeito a dificuldades similares, esse cálculo de custos e benefícios é também relevante para as SNN, quando então se trata não de coibir, pura e simplesmente, uma atividade que se julgue socialmente nociva, mas sim de minimizar custos de diversas ordens - perda, salvamento, prevenção e risco.

Uma vez que os postulados metodológicos da análise econômica do direito sejam levados às suas últimas implicações, parece em certa medida inevitável que em tal análise se faça uso de conceitos estranhos à tradição legal e às leis inspiradas por essa tradição. Por outro lado, conceitos caros à doutrina jurídica podem, à luz da análise econômica, revelar-se secundários ou até mesmo irrelevantes. Paradoxalmente para uma "análise econômica dos contratos celebrados em situação de necessidade", esse é o caso do conceito de necessidade, deixado à sombra por uma análise ocupada com os custos e benefícios de atividades anteriores à realização do 
contrato. É o caso, também, do conceito de lesão que, como repartição anormal ou exageradamente vantajosa para uma das partes do excedente proporcionado pelo contrato, tem como resultado uma realocação de recursos em si mesma irrelevante para a eficiência dos contratos.

É supérfluo afirmar que a análise econômica dos contratos não deva ser, apenas pela estranheza de seus pressupostos, sumariamente rechaçada, tanto quanto se faz supérfluo alertar para a indesejabilidade, por incompatível com a razão de ser mesma de qualquer investigação, de uma adesão acrítica. Mas é também uma condição da crítica a de que os pressupostos da análise que constitua o seu objeto (bem como os da crítica mesma!) sejam, tanto quanto possível, aclarados. Essa última é a tarefa para a qual o presente artigo pretendeu contribuir.

\section{Exploitation and necessity in contractual relationships: some thoughts on the economic analysis of exploitative contracts}

\section{Abstract}

The paper addresses the economic analysis of contracts concluded in a situation of need. In the first part, it focuses the relationship between the concept of a contract made under need and the distribution of the contractual surplus, as well as the proposal, advocated by, among others, Trebilcock and, with some qualifications, Craswell, according to which courts should limit their intervention to the contracts resulting from situational monopoly. It is argued that this proposal is flawed, since it does not render clear which treatment should be dispensed to the cases of nonsituational (or "structural") monopoly usually not envisaged by antitrust governmental agencies. Another problem is that, in the cases of situational monopoly, one of the efficiency reasons for governmental repression of monopolies in general is lacking. The second part of the article deals with the argument for judicial intervention in holdup contracts - which is developed, among others, by Shavell - as a measure for minimizing costs that are, in great part, borne by the parties before the circumstances under which the contract are celebrated take place. This part examines the concepts of engineered situation of need, nonengin- 
nered situation of need and social cost in order to stress the role, not always made explicit, of some assumptions for an analysis in which such concepts are employed.

Keywords: Contractual Holdup. Economic Analysis of Law. Situational Monopoly. Engineered Situations of Need. Social Cost.

\section{Referências}

AIVAZIAN, V. A.; TREBILCOCK, M. J.; PENNY, M. The law of contractual modifications: the uncertain quest for a bench mark of enforceability. Osgoode Hall Law Journal, Toronto, v. 22, n. 2, p. 173-212, 1984.

BENSON, P. Abstract right and the possibility of a nondistributive conception of contract: Hegel and contemporary contract theory. Cardozo Law Review, New York, v. 10, n. 5-6, p. 1.077-1.198, 1989.

BOARDMAN, A. et al. Cost-benefit analysis: concepts and practice. 4. ed. Nova Iorque: Prentice-Hall, 2010.

BOURDIEU, P. Méditations pascaliennes. Paris: Le Seuil, 1997.

BUCKLEY, F. H. Three theories of substantial fairness. Hofstra Law Review, New York, v. 19, p. 33-66, 1990.

COELHO, F. U. Curso de direito civil. São Paulo: Saraiva, 2003. v. 1.

COOTER, R.; ULEN, T. Law e economics. 4. ed. Boston: A. Wesley, 2004.

CRASWELL, R. Remedies when contracts lack consent: autonomy and institutional competence. Osgoode Hall Law Journal, Toronto, v. 33, n. 2, p. 209-235, 1995.

CSERNE, P.; SZALAI, A. On the necessity of necessity: an economic analysis of contracts concluded in a situation of need. Silesian Journal of Legal Studies, Bankowa, v. 2, p. 11-25, 2010.

DWORKIN, R. A matter of principle. Cambridge: Harvard, 1985.

ESPOSTO, A. G. Contracts, necessity and ex ante optimality. European Journal of Law and Economics, New York, v. 9, n. 2, p. 145-156, 1999. 
GORDLEY, J. Equality in exchange. California Law Review, Los Angeles, v. 69, n. 6, p. 1.587-1.656, 1981.

HART, H. L. A.; HONORÉ, T. Causation in the law. 2. ed. Oxford: Clarendon, 1985.

KAPLOW, L.; SHAVELL, S. Why the legal system is less efficient than the income tax in redistributing income. The Journal of Legal Studies, Oxford, v. 23, n. 2, p. 667-682, 1994.

LANDES, W. M.; POSNER, R. A. Salvors, finders, good samaritans and other rescuers: An economic study of law and altruism. The Journal of Legal Studies, Oxford, v. 7, n. 1, p. 83-128, 1978.

POSNER, R. A. The social costs of monopoly and regulation. The Journal of Political Economy, Illinois, v. 83, n. 4, p. 807-828, 1975.

SHAVELL, S. Contractual holdup and legal intervention. The Journal of Legal Studies, Oxford. v. 36, n. 2, p. 325-354, 2007.

SILVA, L. R. F. Revisão dos contratos: do código civil ao código do consumidor. Rio de Janeiro: Forense, 1999.

TREBILCOCK, M. J. The limits of freedom of contract. Cambridge: Harvard, 1993.

TULLOCK, G. The welfare costs of tariffs, monopolies, and theft. Western Economic Journal, Fountain Valley, v. 5, n. 3, p. 224-232, 1967.

WERTHEIMER, A. Exploitation. Princeton: Princeton, 1996. 


\section{Para publicar na revista Prismas: Direito, Políticas}

Públicas e Mundialização, acesse o endereço eletrônico www.publicacoesacademicas.uniceub.br. Observe as normas de publicação, para facilitar e agilizar o trabalho de edição. 